\title{
Chandipura Virus' Oncolytic Potential in Experimentally Induced Tumor in Mice
}

\author{
Anukumar Balakrishnan ${ }^{\mathrm{a}}$ Nikita Malik ${ }^{\mathrm{b}}$ \\ aCMR-National Institute of Virology-Kerala Unit, Govt.T.D.Medical College Hospital, Alappuzha, India; \\ bepartment of Chemistry, University of Massachusetts Amherst, Amherst, MA, USA
}

\section{Keywords}

Oncolytic virus · Chandipura virus · Cancer therapy

\begin{abstract}
Chandipura virus (CHPV) is a tropical pathogen, suggesting its involvement in childhood encephalitis syndrome in India. No reports are available in adult human beings for its pathogenicity. Similarly, in adult mice, the virus does not develop pathogenesis by parenteral route except for intracranial route of infection. The virus is remarkably nonpathogenic to adult immunocompromised nude mice. In vitro in tissue culture, the CHPV infects and kills many types of cells. All of these properties could qualify the CHPV to be a candidate virus for tumor therapy. To prove this, an experimentally induced tumor in a mouse was infected with live CHPV. The results showed that intra-tumoral injection reduced the volume of tumor and increased the longevity of the mice. The study concludes that the CHPV may be a safe tumor therapy virus. More precisely, the discovery of CHPV protein with oncolytic potential may lead to the development of novel drugs/therapeutics.
\end{abstract}

(c) 2020 S. Karger AG, Basel

\section{Introduction}

Cytopathic effects, especially cell lysis, are often seen as a pathogenic effect of a particular virus. Diverting that of cancer specific, however, would be a cancer treatment technique. The idea of using viruses in the cancer care dates back to the beginning of the 20th century when spontaneous regression of tumor was found in patients with malignancies following vaccination with rabies or viral infection $[1,2]$. Laboratory studies have confirmed the lysing of experimentally induced murine tumors with Newcastle disease virus and influenza virus [3]. An oncolytic virus exclusively infects and lyses the cancer cells, while the normal cells remain unharmed. Oncolytic viruses derive their specificity by exploiting cell surface receptor or intracellular aberrations in gene expression that arise in malignancies during tumor development [4]. Despite the defects in apoptosis-inducing gene(s), many tumor cells retain the apoptotic signaling pathway intact. Thus, if an effective apoptotic signal is given, these tumor cells will die [5]. The greatest benefit of the oncolytic virus is its capacity to be modified in response to the requirements by in vitro genetic manipulation [6]. Many oncolytic viruses were either a wild virus or a genetically engineered virus [7]. To date, 2 genetically modified oncolytic viruses are licensed for marketing as a drug. First one is Oncorine (E1B-deleted adenovirus) [8] and the second one is T-vec (Talimogene laheparepvec), a second-generation oncolytic herpes simplex virus type 1 armed with GM-CSF. It was recently approved in the USA and Europe as the first oncolytic virus drug $[9,10]$.

Chandipura virus (CHPV, family Rhabdoviridae and genus vesiculovirus) is associated with acute encephalitis and fatal in young children residing in Andhra Pradesh, karger@karger.com

www.karger.com/int

Karger" (c) 2020 S. Karger AG, Base

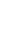

Anukumar Balakrishnan 
Maharashtra, and Gujarat $[11,12]$. Children under the age of 15 years are susceptible; adults, being refractory to the natural infection. Similarly, mice susceptibility studies showed that the CHPV was lethal to young mice, but adults were only susceptible to infection through the intracranial route [13]. CHPV induces cell death in a variety of cell lines, such as Vero, baby hamster kidney (BHK), RAW, rhabdosarcoma, etc [14]. Susceptibility to broad spectrum cells and nonpathogenic to adult animals support its use in oncotherapy. In this study, we tested the CHPV in the mice model for the utility of an oncolytic agent.

\section{Methods}

\section{Cells and Virus}

Vero E6 \& BHK (clone 21) cell lines were obtained from the National Center for Cell Science, India. The cells were cultured and maintained in Dulbecco's modified Eagle's medium, supplemented with $10 \%$ Fetal Calf Serum (FCS, Gibco, Ireland). The CHPV strain (NIV id. 034267) was originally isolated from the Andhra Pradesh outbreak [11]. The virus propagated and maintained in Vero E6 cells was used in this study.

\section{Induction of Tumor in Nude Mice}

The NIH nude mice, 30-day-old males, were used in this experiment. The study was carried out in strict accordance with the recommendations of the Committee for the Purpose of Control and Supervision of Experiments on Animals (CPCESA), India, and the protocol was approved by the Institute Animal Ethics Committee (IAEC), National Institute of Virology, Pune. All efforts were made to minimize the suffering of mice. The mice were injected with 1 million BHK cells via subcutaneous (sc) route in the back region just above the head of the tail. The cells were allowed to grow in the mouse. Size of the visible tumor was measured on the 14th day after injection by taking a longitudinal (l) and transverse ( $\mathrm{t}$ ) length (in $\mathrm{mm}$ ) using digital caliber and the volume was calculated using the formula $\left(1+t^{2}\right) / 2$. On the 14 th day post induction of tumor, the mice were divided into 2 groups. A group of mice $(n=6)$ was injected with $25 \mu \mathrm{L}\left(10^{7} \mathrm{pfu} / \mathrm{mL}\right)$ of the CHPV each in 4 different sites on the tumor, and the other group $(n=3)$ was injected with Dulbecco's modified Eagle's medium and used as an uninfected control. The tumor size was measured at an interval of 7 days up to 28 days PI. The volume was expressed in $\mathrm{mm}^{3}$. The experiment was repeated twice, and survival statistics were performed in GraphPad Prism 5.04, GraphPad Software, San Diego, CA, USA.

\section{Result}

On 14th day post-injection of cells in nude mice, the tumor formed by the BHK cells was $30-50 \mathrm{~mm}^{3}$ in size. The same day was considered as day zero and the tumor

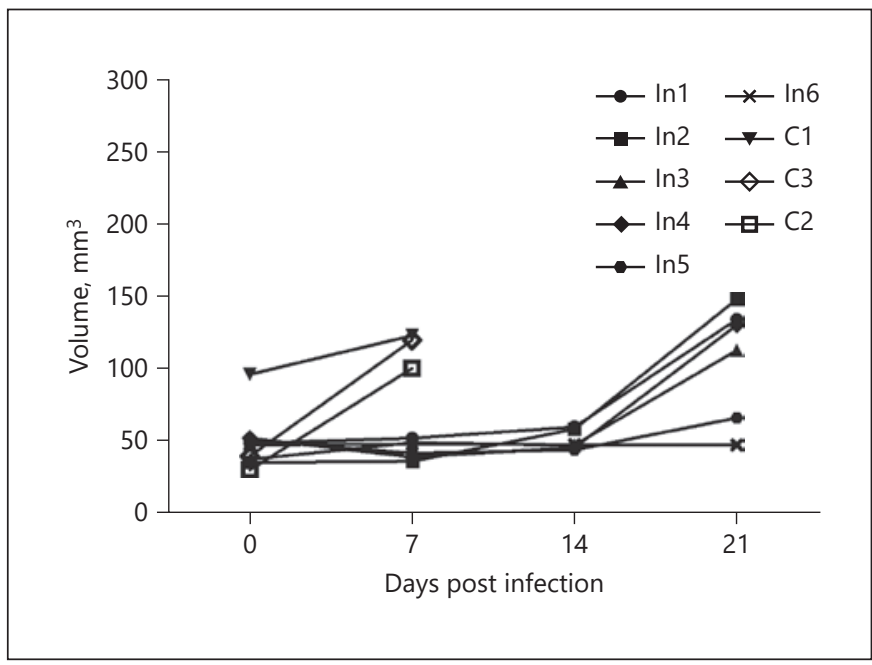

Fig. 1. Reduction in volume of tumor infected with CHPV in mice. In nude mice the tumor was induced and then infected with CHPV (In). The uninfected tumor-bearing mice were kept as a control group $(\mathrm{C})$. The tumor was measured using a digital caliber to take longitudinal (l) and transverse ( $\mathrm{t}$ ) lengths (in $\mathrm{mm}$ ), and the volume was determined using the formula $\left(1+t^{2}\right) / 2$. The graph showing individual mouse tumor volume at different time points. The experiment was replicated twice and the findings were identical. CHPV, Chandipura virus.

was infected with the virus. In the graph, the interval was determined after virus infection (shown in Fig. 1). The tumor progressed rapidly in the control group mice and reached the size of $100-120 \mathrm{~mm}^{3}$ at 7 th day post-infection (21st day post tumor induction). The control mice subsequently died. The infected mice, however, displayed no substantial tumor development up to 14 days PI (28 days post tumor induction). The tumor volume on 7 th and 14th day PI ranged from 38 to 51 and $43-60 \mathrm{~mm}^{3}$ respectively. Subsequently, on 21 st day PI (35th day post tumor induction) the tumor grew and reached a size of 47-148 $\mathrm{mm}^{3}$. Some of the infected mice survived up to 23 days PI. In the infected mice, the median survival time was 22 days and greater than control mice (12 days) $(p<0.0005)$ (shown in Fig. 2).

\section{Discussion}

The CHPV had been tested for its oncolytic ability in a mouse tumor model. However, the virus stopped the tumor progression for some time but later failed to stop the tumor progression. The mean survival time in the mice infected with CHPV was doubled compared with the mice not infected with CHPV. The results upheld 


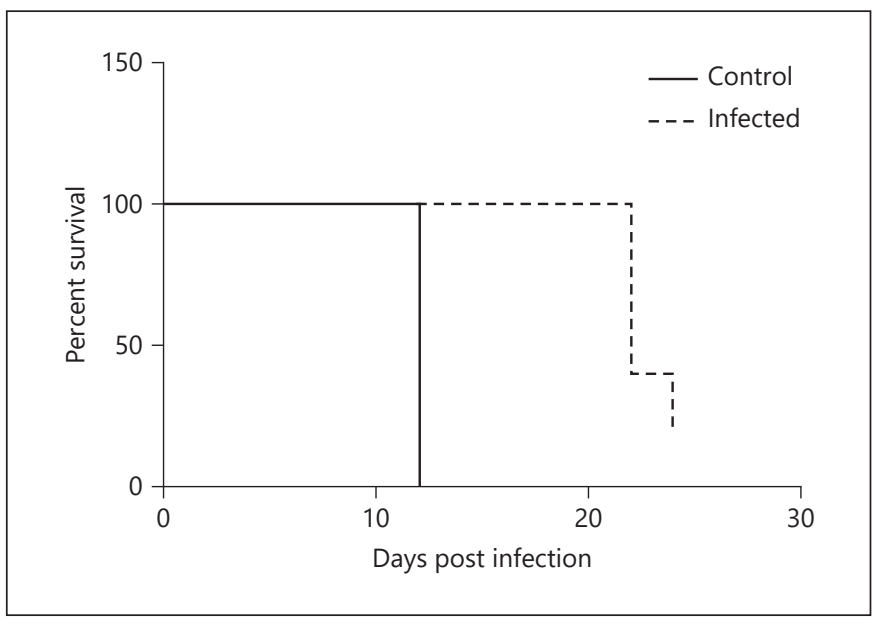

Fig. 2. CHPV-infected tumor-bearing nude mice survive longer than uninfected mice. The percent survival of infected and uninfected mice was measured in GraphPad Prism software v 5.04 using survival statistics application. There was a statistically significant difference between the infected group and uninfected group in longevity using the Kaplan-Meier survival analysis $(p<0.0005)$. CHPV, Chandipura virus.

CHPV's oncolytic potential. We were not able to establish any specific mechanism of oncolysis action by CHPV. Nonetheless, we say that predilection of CHPV to specific cell types and killing the infected cells may be the possible mechanism of action. Oncolytic viruses mediate several possible pathways for the destruction of tumor cells [15]. As a result of viral replication, the virus itself is capable of directly lysing the cells. CHPV does not replicate in nude mice, but it may have been replicated in the BHK cells in the tumor. Replication of the virus may allow progressive infection of surrounding tumor cells and may lead to cell lysis in a higher percentage of cells. Cell lysis mediated by virus replication may be attributed for regression of tumors. When the immune system cleansed the virus, the tumor grew, killing the mice carrying the tumor. Early production of CHPV-specific IgM clears the virus from the circulation [13]. In the cancer treatment, cytopathic effect such as cell lysis can be exploited. Oncolytic virus has the property of infecting and killing the cancer cells without harming the normal cells. The CHPV has broad spectrum cell susceptibility and kills the transformed cells [14]. Nonpathogenicity to the adult humans and animals $[11,16]$ further convinces the usefulness of CHPV as a safe candidate for oncotherapy with viruses.

The study concludes that CHPV could be a potential cancer therapy agent. Because of its selective killing of tumor cells, this virus could be used to remove residual tumor cells from an area where the tumor has been removed by surgical procedures. The results confirmed the oncolytic potential of the CHPV even though the data are preliminary.

\section{Acknowledgements}

The study received support through extramural funding from the Department of Science and Technology, India. Throughout the research the author honors the director of NIV for his moral support and encouragement. The author is grateful to all NIV Pune staff for their support during the study.

\section{Statement of Ethics}

The study was carried out in strict accordance with the recommendations of the Committee for the Purpose of Control and Supervision of Experiments on Animals (CPCESA), India, and the protocol was approved by the Institute Animal Ethics Committee (IAEC), National Institute of Virology, Pune. All efforts were made to minimize the suffering of mice.

\section{Conflict of Interest Statement}

The authors declare that there are no conflicts of interest.

\section{Funding Sources}

The study received support through extramural funding from the Department of Science and Technology, India.

\section{Author Contributions}

Dr. Anukumar B. designed the study, analyzed the data, and wrote the manuscript. Dr. Nikita performed the experiments.

\section{References}

1 Dock G. The influence of complicating diseases upon leukæmia. Am J Med Sci. 1904; 127(4):563-92.

2 DePace N. Sulla scomparsa di un enorme cancro vegetante del collo dell'utero senza cura chirurgica. Ginecologia. 1912;9:82-9.

3 Sinkovics J, Horvath J. New developments in the virus therapy of cancer: a historical review. Intervirology. 1993;36(4):193-214.

4 Russell SJ, Peng KW. Viruses as anticancer drugs. Trends Pharmacol Sci. 2007;28(7): 326-33.
Balakrishnan/Malik 
5 Quintieri L, Fantin M, Vizler C. Identification of molecular determinants of tumor sensitivity and resistance to anticancer drugs. Adv Exp Med Biol. 2007;593:95-104.

6 Bell J, Lichty B, Stojdl D. Getting oncolytic virus therapies off the ground. Cancer Cell. 2003;4(1):7-11.

7 Singh PK, Doley J, Kumar GR, Sahoo AP, Tiwari AK. Oncolytic viruses \& their specific targeting to tumour cells. Indian J Med Res. 2012;136(4):571-84.

8 Heise C, Sampson-Johannes A, Williams A, McCormick F, Von Hoff DD, Kirn DH. ONYX-015, an E1B gene-attenuated adenovirus, causes tumor-specific cytolysis and antitumoral efficacy that can be augmented by standard chemotherapeutic agents. Nat Med. 1997;3(6):639-45.
9 Fukuhara $\mathrm{H}$, Ino $\mathrm{Y}$, Todo T. Oncolytic virus therapy: a new era of cancer treatment at dawn. Cancer Sci. 2016;107(10):1373-9.

10 Coffin R. Interview with Robert Coffin, inventor of T-VEC: the first oncolytic immunotherapy approved for the treatment of cancer. Immunotherapy. 2016;8:103-6.

11 Rao BL, Basu A, Wairagkar NS, Gore MM, Arankalle VA, Thakare JP, et al. A large outbreak of acute encephalitis with high fatality rate in children in Andhra Pradesh, India, in 2003, associated with Chandipura virus. Lancet. 2004;364(9437):869-74.

12 Chadha MS, Arankalle VA, Jadi RS, Joshi MV, Thakare JP, Mahadev PV, et al. An outbreak of Chandipura virus encephalitis in the eastern districts of Gujarat state, India. Am J Trop Med Hyg. 2005;73(3):566-70.
13 Anukumar B, Mishra AC. Immune response during acute Chandipura viral infection in experimentally infected susceptible mice. Virol J. 2008;5(121):1-11.

14 Jadi RS, Sudeep AB, Kumar S, Arankalle VA, Mishra AC. Chandipura virus growth kinetics in vertebrate cell lines, insect cell lines \& embryonated eggs. Indian J Med Res. 2010;132: 155-9.

15 Kirn DH. Replicating oncolytic viruses: an overview. Expert Opin Investig Drugs. 1996; 5:753-62.

16 Bhatt PN, Rodrigues FM. Chandipura virus: a new arbovirus isolated in India from patients with febrile illness. Indian J Med Res. 1967;55: 1295-305. 